\title{
AFINAL, O QUE FAZ O SERVIÇO SOCIAL NA SAÚDE MENTAL?
}

\author{
AFTER ALL, WHAT DOES SOCIAL WORK IN MENTAL HEALTH?
}

Lucia Cristina dos Santos Rosa ${ }^{1}$

Amanda Furtado Mascarenhas Lustosa ${ }^{2}$

\begin{abstract}
RESUMO
Este ensaio tem por objetivo sistematizar algumas reflexões suscitadas pela crescente indagação, sobretudo de estudantes de Serviço Social, acerca do fazer do assistente social na saúde mental. Tece alguns comentários sobre aspectos que são pertinentes à agenda do Serviço Social no campo da Saúde Mental e promove algumas reflexões pontuais e que merecem maior visibilidade para ganhar melhores investimentos. Tem por base a experiência das autoras no campo da Saúde Mental, no contexto nordestino, sobretudo no contexto piauiense e interlocuções com profissionais de outras regiões.
\end{abstract}

PALAVRAS-CHAVE: Serviço Social. Prática Profissional. Saúde Mental. Reforma Psiquiátrica.

\begin{abstract}
This essay aims to systematize some reflections raised by the growing inquiry, especially students of Social Work, about the making of social workers in mental health. Makes some comments on aspects that are relevant to the agenda of social work in the field of mental health and provides some reflections off and visibility they deserve to win best investments. It is based on the authors' experience in the field of mental health within the Northeast, especially in the context of Piauí and dialogues with professionals from other regions.
\end{abstract}

KEYWORDS: Social Work, Professional Practice, Mental Health, Psychiatric Reform.

\section{SAÚDE MENTAL: AINDA UMA ÁREA DELICADA PARA O SERVIÇO SOCIAL BRASILEIRO?}

A produção recente de autores do Serviço Social brasileiro tem contribuído, embora morosamente, no acúmulo teórico e reflexivo da profissão no interior do movimento da reforma psiquiátrica brasileira. Não obstante, dispõe-se de um acervo ainda limitado, com parcos elementos para o debate sobre as múltiplas inserções dos assistentes sociais nos diferentes espaços sócio ocupacionais do campo da Saúde

\footnotetext{
${ }^{1}$ Docente do Departamento de Serviço Social da Universidade Federal do Piauí - Doutora em Serviço Social pela UFRJ. Pós-Doutoranda pelo Departamento de Saúde Coletiva UNICAMP. Telefone 86 32155784, e-mail: luciacsrosa@yahoo.com.br.

2 Assistente Social formada pela Universidade Federal do Piauí, mestranda em Políticas Públicas pela Universidade Federal do Piauí. E-mail: Amanda-facime@hotmail.com.

Serv. Soc. \& Saúde, Campinas, SP v. 11, n. 1 (13), p. 27-50 jan./ jun. 2012 ISSN 1676-6806
} 
Mental, um campo ainda delicado para muitos colegas do Serviço Social, posto o passado recente, anterior ao movimento de reconceituação, que o vincula à psicologização do social. O risco desta leitura ainda persiste, pois no campo do Serviço Social a apropriação do tema da subjetividade, das emoções e dos aspectos relacionais não está equacionado no interior da profissão, como bem mostrou Vasconcelos (2000).

Ademais, em algumas equipes de Saúde Mental há a hegemonia de determinados marcos teóricos, tais como algumas vertentes das terapias de famílias e terapias sistêmicas, que parecem oferecer respostas que técnica e subjetivamente, supostamente, aplacam a angustia que comumente acompanha os profissionais do campo.

Neste contexto, observa-se que muitos profissionais, inclusive do Serviço Social, são impulsionados a realizar uma formação específica, com base nestes referenciais, até mesmo para se sentirem à vontade no campo, dada a hegemonia posta e pelo fato de muitos supervisores clínico-institucionais, a maioria não assistentes sociais, terem sua formação e orientação baseadas em campos estranhos para o Serviço Social.

Tais cenários trazem questões ambíguas e desconfortáveis para muitos assistentes sociais que, de um lado, precisam ter instrumentos, ferramentas técnicas, para dialogar com estes colegas e com as teorias hegemônicas em alguns serviços de Saúde Mental. De outro lado, são instados a oferecer respostas tecnicamente apropriadas, tais como no manejo de trabalho grupal, como demonstra Eiras (2009), ou grupos operativos e de famílias, para os quais a profissão, num período mais recente, não apresentou uma instrumentalidade condizente com os anseios mais imediatos de uma parte significativa da categoria. Tal fato tem se mostrado mais evidente no reconhecimento do hiato entre o projeto ético-político da profissão, mais associado à academia, e os profissionais “da ponta”, exigidos a executar as políticas públicas e que demandam por instrumentalidade de seu fazer, arriscando reduzi-la às “receitinhas” ou ao velho metodologismo, fartamente criticado pelo corpo teórico-crítico do Serviço Social.

Com relação às respostas de cunho terapêutico que alguns profissionais ofereciam no cotidiano da Saúde Mental, a Resolução nº 569, de 25 de março de 2010 do Conselho Federal de Serviço Social, vedou tais práticas associadas ao título e/ou ao exercício do assistente social (CFESS, 2011).

Mas, para além de qualquer marco legal, observa-se que o alcance terapêutico de muitas práticas e ações dos assistentes sociais na Saúde Mental é reconhecido tanto por Serv. Soc. \& Saúde, Campinas, SP v. 11, n. 1 (13), p. 27-50 jan./ jun. 2012 ISSN 1676-6806 
profissionais de outras categorias profissionais, como admite Ramos (2003), quanto pelos próprios usuários dos serviços, ao reconhecer, por exemplo, o efeito catártico de uma "escuta qualificada”.

Acolhimento, escuta qualificada, vínculo, dentre outros, são conceitos adotados por muitos profissionais do Serviço Social, mas identificados, por exemplo, por Ana Elizabete Mota, em uma palestra que proferiu no Piauí, em 2009 ou 2010, a convite do CRESS-PI, como sendo estranhos ao Serviço Social. Contudo, são adotados pela Política Nacional de Humanização (2004), que também tem exigido uma qualificação específica de todos os profissionais, no trato com a dimensão da subjetividade, até mesmo pelo reconhecimento da crescente violência simbólica a que são submetidos os usuários e pelos profissionais da saúde em geral, a começar pela precariedade de vínculos trabalhistas e condições de trabalho aviltadas.

Novos conceitos e as demandas específicas de certas políticas públicas, sobretudo no campo subjetivo, colocam para o assistente social equacionar dimensões que a formação profissional generalista do Serviço Social, na graduação, nem sempre oferece resposta. São demandas às quais muitos assistentes sociais não conseguem responder de maneira crítica, até pela dinâmica do próprio cotidiano, que exige respostas imediatas e carrega uma marca da reiteração bastante significativa, conforme esclarece Heller (1989).

Supõe-se, porém, que tais exigências tendem a mudar a concepção de mundo e referências dos assistentes sociais da mesma maneira que estes podem também trazer novos marcos para as políticas e práticas institucionais, desde que fundamentados em um referencial teórico-metodológico que ofereça suporte para tanto.

No entanto, há também que trazer os tensionamentos que, por exemplo, um assistente social que também tem outra formação superior, por exemplo, em Psicologia pode trazer para o Serviço Social, fato que contemporaneamente tem sido muito comum.

Toda essa digressão panorâmica teve a intenção de apresentar e circunscrever alguns desafios que estão postos para o Serviço Social, com destaque para a Saúde Mental.

De qualquer maneira, os impasses estão postos. O Serviço Social é uma profissão predominantemente interventiva, sendo exigido a dar respostas às múltiplas expressões da questão social. A resposta aos impasses identificados deverá ser Serv. Soc. \& Saúde, Campinas, SP v. 11, n. 1 (13), p. 27-50 jan./ jun. 2012 ISSN 1676-6806 
construída pelo coletivo da categoria, cabendo a este artigo pontuar alguns elementos para o debate, tensionando-os sem a intenção de oferecer respostas conclusivas.

Alguns avanços podem ser registrados na literatura do Serviço Social, dentre os quais, o consenso de que há sintonia/convergência entre o ideário da Reforma Psiquiátrica brasileira com os fundamentos do projeto ético-político do Serviço Social, haja vista vários princípios em comum, destacando-se: 1) a liberdade como valor basilar, inscrito na palavra de ordem do movimento da luta antimanicomial "a liberdade é terapêutica”, impondo o cuidado comunitário, em contraponto a modelos segregadores/ excludentes que se calcaram na presunção da periculosidade e incapacidade para forjar uma modalidade de tratamento que desabilitou a pessoa com transtorno mental para o convívio social, gerando vários tipos de violação de direitos humanos e consequentemente uma dívida histórica do Estado para com esse segmento; 2) a defesa intransigente dos direitos humanos; 3) a luta pela eliminação de todas as formas de preconceito, na perspectiva de contribuir para a construção de outra relação entre a sociedade e o louco/loucura, mudando o imaginário social; e 4) empenho na garantia da qualidade dos serviços prestados, haja vista o crescente desinvestimento do Estado em gastos sociais e precarização das relações de trabalho (CRESSRJ, 2005).

O reconhecimento de que o sofrimento humano tanto dos usuários dos serviços quanto dos trabalhadores/profissionais da área da saúde, incluindo o assistente social, conforme Resolução ${ }^{\circ}$ 287/98, expresso em conceitos como o burnout, impõe demanda no campo da subjetividade, requerendo do Serviço Social maiores investimentos no plano teórico-metodológico; técnico-operativo e ético-político, como parte constitutiva da condição humana e da totalidade social, subtraindo-se a mera perspectiva de psicologilização ou psiquiatrização dos problemas humanos.

Estudiosos como Vasconcelos (2000) mostram que os assistentes sociais integraram historicamente as equipes de Psiquiatria/Saúde Mental. Muitos fundamentaram suas atividades, tendo por base o campo psi, alguns investindo em formação na esfera da psicanálise e terapia de família.

Pereira (2000) mostra os limites dos referencias teóricos das vertentes das terapias de famílias, associadas à prática liberal de consultório, ao ideário da classe média, sem conseguir dar conta das questões de gênero e da multiplicidade de arranjos familiares da atualidade.

As várias perspectivas de terapias de famílias têm limites claros no trato com a população pauperizada, que nem sempre compreende o significado de ir para um Serv. Soc. \& Saúde, Campinas, SP v. 11, n. 1 (13), p. 27-50 jan./ jun. 2012 ISSN 1676-6806 
serviço e "somente falar" de seu sofrimento, ação que, superinvestida por muitos profissionais, tende a saturar rapidamente. Respondem muito mais positivamente a serviços que desenvolvam atividades baseadas em técnicas manuais, corporais, dramáticas (teatrais), que permitam as múltiplas expressões dos determinantes sociais do seu processo saúde-doença, desde que se associem também à esfera lúdica. Tais contornos vão exigir do assistente social trabalho em equipe, pelo menos multiprofissional, e criatividade, num contexto de desencanto, que se intensifica pelo baixo investimento no Sistema Único de Saúde, dado o avanço do ideário neoliberal, com as crescentes privatizações, retração de direitos sociais e baixo investimento em uma cultura pública democrática, observada na crescente procura pelos planos privados de saúde e parca luta coletiva em torno dos serviços públicos de saúde e educação.

Não há muito que acrescentar com relação ao que a literatura do Serviço Social tem acumulado em relação à crítica ao Serviço Social Médico e Clínico, bem retratado nos textos O Serviço Social Clínico e o projeto ético-político do Serviço Social (CRESS-RJ, 2003) e Atribuições privativas do Assistente Social e o Serviço Social Clínico (CRESSRJ, 2004).

Ressalva-se que na Saúde Mental, como em qualquer outra clínica, o assistente social necessita se apropriar de conhecimentos psicopatológicos, psicofarmacológicos e de determinados “jargões”. Conhecer as várias lutas interteóricas e clínicas, em disputa no campo, até para poder dialogar com a equipe, mas sem se subalternizar a esses saberes ou a seus profissionais, como, às vezes, se observa, quando um assistente social adota terminologia específica de outras profissões para processar seus registros profissionais, fato que ainda acontece sobremaneira pelo uso acrítico de termos como “anamnese” social, “embotamento”, dentre outros.

No mesmo diapasão, também se observa o risco à descaracterização/ desprofissionalização de alguns profissionais, ao se constatarem registros de assistentes sociais em prontuários, sobre suas intervenções de maneira genérica, vaga, sem o emprego de nenhuma análise social mais ampla, contextual ou termo técnico que pudesse diferenciá-lo de outras categorias profissionais, por exemplo.

Neste contexto, o social fica diluído, fluido, desqualificado, como sendo tudo e nada ao mesmo tempo. Alguns assistentes sociais desenvolvem suas intervenções sem uma análise social balizada, sem um “diagnóstico” de realidade fundamentado que possa orientar suas estratégias de intervenção. 


\section{Serviço Social e Clínica Ampliada na Saúde Mental}

Com as mudanças internas do objeto da Psiquiatria do transtorno mental para a Saúde Mental, a partir da Segunda Guerra Mundial, o social ganha relevo tal como expresso no conceito de Psiquiatria Social.

O campo clínico e extra clínico se fundem, exigindo uma visão ampliada da pessoa enferma para além dos sintomas clínicos, para sua "existência sofrimento" (ROTELLI, 1990).

Mas, como definir Saúde Mental?

Não há um conceito oficial. Nos documentos da Organização Pan Americana de Saúde (OPAS, 2001), a Saúde Mental é retratada como "algo mais que a ausência de transtorno mental”, de maneira vaga. A Saúde Mental seria o contraponto do transtorno mental, estando relacionada a determinantes sociais, econômicos, políticos, culturais e teóricos.

Apesar da generalidade do conceito e dificuldade de precisá-lo, navegando pela Internet, é possível elencar uma série de indicadores que são sugeridos como critérios de saúde mental. Todos relacionados a um sujeito abstrato, descontextualizado, aproximando-se do conceito igualmente genérico da OMS de que saúde seria um estado de completo bem-estar. Destarte, a Saúde Mental estaria relacionada a:

- a capacidade de um indivíduo de apreciar a vida;

- sentirmo-nos bem conosco próprio e na relação com os outros;

- sermos capazes de lidar de forma positiva com as adversidades;

- termos confiança e não temermos o futuro;

- atitudes positivas em relação a si próprio;

- crescimento, desenvolvimento e auto realização;

- integração e resposta emocional

- autonomia e autodeterminação

- percepção apurada da realidade

- domínio ambiental e competência social;

Estes indicadores parecem ter relação com os manuais de autoajuda, exigindo uma atitude otimista do indivíduo nas suas relações consigo mesmo, com os outros e com seu ambiente, numa perspectiva ecológica. O indivíduo seria o centro de tudo, autocentrado, cuja percepção e concepção definiriam suas relações com o mundo. Logo, 
em caso de fracasso, a culpabilização, a responsabilização do mesmo pela sua leitura e práticas equivocadas estaria dada à priori. Os determinantes sociais do processo saúde doença-atenção são ignorados, ou tratados de maneira derivada da percepção e domínio do indivíduo, em relação a seu meio.

A partir dos anos 90 do século passado, no Brasil, como conquista dos movimentos sociais, no cerne do processo de redemocratização do país, emerge o campo da atenção psicossocial, que Saraceno (1999) traduz como sinônimo de cidadania.

Mas, há várias concepções de atenção psicossocial.

Roberto Tikanori a define como um processo de restituição contratual da pessoa com transtorno mental. Por sua vez, Ana Pitta (1996) remete-a para o campo da ética, da estética e de uma atitude compreensiva, implicando um processo complexo relacionado ao combate ao estigma.

Saraceno (1999) delimita-o de maneira tripartite, destacando: o morar, o trocar identidades e o apropriar-se da cidade/espaço urbano, produzindo valores socialmente cambiáveis.

Tais entendimentos corroboram a delimitação do conceito ampliado de saúde imposto pela institucionalização do Sistema Único de Saúde, a partir da Constituição Federal de 1988, quando a saúde passa a ser associada aos determinantes sociais do processo saúde-doença.

O social, então, compõe o cenário de atuação de todas as profissões, não apenas do Serviço Social, exigindo do assistente social melhor explicitação da forma de conceber o social, bem como redesenhar seu lugar na saúde mental, no contexto do cuidado comunitário.

Observa-se que alguns segmentos do Serviço Social apresentam sérias restrições a qualquer alusão ao conceito psicossocial e também ao termo clínico, no seio da categoria, remetendo-os, muitas vezes, ao campo do conservadorismo, rótulo que tem obstaculizado o avanço do debate "respeitoso e fraterno", como denomina Iamamoto. Acreditamos que tal fato deriva do espectro recente que ronda a profissão, ainda não totalmente superado, muito vinculado à leitura hegemônica da psicologização do social e também à visão restrita da atuação do Serviço Social a determinadas patologias, remetido no geral ao Serviço Social Médico. Mas uma visão de totalidade inclui a 
dimensão psi, a dimensão emocional, afinal, o ser humano apresenta-se a nós no cotidiano profissional como um ser integral.

A dimensão psi emocional está presente nas relações cotidianas dos profissionais entre si e destes com seus usuários, mediando o seu fazer. A dimensão psi implica o trabalho intrapsíquico, inconsciente, mas também questões conscientes e contextuais. Tais implicações sinalizam para a importância do trabalho conjunto, em equipe, o que é requerido pelos novos processos de trabalho, no contexto da reforma psiquiátrica, o que comumente é efetivado neste cenário entre, na primeira dimensão, por um profissional da Psicologia e, na segunda dimensão, pelo assistente social.

Evidentemente, nem sempre esse trabalho é tranquilo, sendo mediatizado, às vezes por tensões, mas também pela colaboração e o trabalho compartilhado. Afinal, como informa Merhy (2007), a principal tecnologia em Saúde Mental é conformada como tecnologias leves "implicadas com a produção das relações entre dois sujeitos, que só têm materialidade em ato” (ibid., p. 94).

Logo, o relacionamento humano é o principal componente do processo de trabalho em saúde. Ele viabiliza as orientações e ações socioeducativas, podendo ou não potencializar mudanças no plano simbólico, em concepções de mundo e valores, e dessa maneira, nas relações sociais mais gerais da sociedade.

No I Encontro Estadual de Serviço Social e Saúde Mental e II Seminário UERJ de Serviço Social e Saúde Mental, realizado no dia 02 de junho de 2010, na UERJ, em debate, uma das principais questões levantadas relacionou-se à indagação se haveria uma clínica do Serviço Social na Saúde Mental.

Graziela Scheffer Machado respondeu que a clínica do Serviço Social na saúde mental é a clínica ampliada. Essa é a clínica que preside o Sistema Único de Saúde, em geral, estando reforçada na Política Nacional de Humanização, na reforma psiquiátrica, dentre outros. Logo, todos os profissionais que atuam no SUS encontram-se sob a égide desta clínica.

A principal questão é como o Serviço Social vem se apropriando da clínica ampliada, sob que matizes e como essa interação Serviço Social e clínica ampliada tem potencializado a identidade do assistente social.

No que consiste à clínica ampliada, é também denominada como clínica da reforma, do cotidiano ou do sujeito?

Gastão Campos concebe-a como a clínica do sujeito, que estaria no centro da ação dos profissionais como "sujeito concreto, não somente marcado por uma biografia Serv. Soc. \& Saúde, Campinas, SP v. 11, n. 1 (13), p. 27-50 jan./ jun. 2012 ISSN 1676-6806 
singular, mas também seu corpo e sua dinâmica corporal estariam marcados por uma singularidade [...] em um dado contexto social específico” (CAMPOS, 2007, p. 54).

Logo, a clínica ampliada, ou da reforma, materializa-se na clínica pautada no sujeito e em suas necessidades. É, consequentemente, usuário-centrada. Amplia o espectro clínico para além das limitações impostas pela enfermidade, colocando em foco a gestão do cotidiano de vida da pessoa enferma.

Consiste em ir para além dos sintomas apresentados e centrar-se nos determinantes sociais do processo saúde-doença, reinventando a vida e produzindo saúde.

\section{O FAZER DO ASSISTENTE SOCIAL NA SAÚDE MENTAL}

O fazer do assistente social na Saúde Mental está multideterminado por uma série de elementos. É determinado por todo um contexto macro societário, no qual se desenham as políticas públicas, numa correlação de forças em que distintos projetos se enfrentam, que conformarão princípios e coordenadas que balizarão os serviços que os implementarão.

Depende do tipo de instituição em que atua. De sua história, da história de organização de sua equipe e da forma como organiza seus processos de trabalho. No modelo hospitalocêntrico, o assistente social tende a assumir funções mais tradicionais, subordinadas, e em apoio ao fazer da categoria médica. Contribui, principalmente, na agilidade da rotatividade dos leitos; promove atividades de educação em saúde; orienta sobre benefícios sociais e previdenciários, atua muito atrelado às famílias e articula a rede socioassistencial.

No campo da atenção psicossocial, tendo por cerne os centros de atenção psicossocial - CAPS, há clivagens na atuação deste profissional, tendo em vista que há vários tipos de CAPS, alguns inclusive não contam com assistente social em sua equipe. Há CAPS cujos processos de trabalho se assemelham à forma de organização do modelo hospitacêntrico, denominado por Lancetti (2008), como CAPS burocrático, muito na mediação do acesso aos benefícios sociais e na porta de entrada e de saída, como define Vasconcelos (2000), apesar de apresentar-se com algumas modernizações. Na maioria destes serviços, os assistentes sociais ficam exclusivamente voltados para as questões no trato com a "pobreza e os pobres”, e nas articulações, para viabilizar o 
acesso e usufruto de direitos, numa relação mais direta com os usuários dos serviços, e na intermediação com a equipe de profissionais e dirigente.

Em CAPS “turbinado” (LANCETTI, 2000), o assistente social tende a atuar como técnico de referência, como todos os profissionais. Essa figura circunscreve o profissional cuidador, que gerencia os projetos terapêuticos de um grupo limitado de usuários, podendo potencializar as interfaces entre as diferentes categorias profissionais, bem como diluir até mesmo certas competências ou atribuições privativas. Alguns assistentes sociais têm vivenciado, inicialmente, tal processo como uma descaracterização de sua identidade profissional original. Outros lutam por agregar à figura do técnico de referência as atribuições exclusivas do assistente social. Mas tal “mal-estar” não é exclusividade do assistente social, como constata Campos et al (2008). O trabalho em

[...] equipe transdisciplinar (no compartilhamento de um campo comum) ocorre em detrimento da valorização das especificidades técnicas do trabalho, deixando os limites entre as categorias profissionais borrados, o que, se não for construído a partir de um núcleo suficientemente consistente de competência nuclear, pode agravar a angústia decorrente desse tipo de trabalho (Ibid., p. 402).

Neste contexto, o assistente social atua sob a égide da clínica ampliada, que impõe a atuação do profissional no território de vida da pessoa com transtorno mental, gerindo outras possibilidades de reinventar a vida, produzir saúde, apesar das limitações que o transtorno mental no geral impõe.

Neste contexto, a relativa autonomia do assistente social em definir o conteúdo e direção do seu trabalho está circunscrita também pelo trabalho em equipe.

A atuação em centros de convivência, um serviço típico do Estado de São Paulo, em programas de geração de renda, vai impor maior atuação com os recursos comunitários, para potencializar a identidade de trabalhador, de produtor de outros valores intercambiáveis socialmente para a pessoa com transtorno mental. Neste contexto, o assistente social atua em conjunto com psicólogos e terapeutas ocupacionais.

Entretanto, temos observado que a história de como se compôs a equipe multiprofissional e teve início um determinado serviço influi no lugar e no fazer dos assistentes sociais. Se o assistente social esteve presente desde o início da criação de um serviço e composição de uma equipe, há maiores chances de construir seu lugar de maneira mais ampla e autônoma. Equipes multiprofissionais que iniciaram juntas e Serv. Soc. \& Saúde, Campinas, SP v. 11, n. 1 (13), p. 27-50 jan./ jun. 2012 ISSN 1676-6806 
contribuíram para construir coletivamente um serviço tendem a construir relações menos hierarquizadas, ao mesmo tempo em que constrói um território de poder mais compartilhado. Os profissionais que se agregam posteriormente tendem a levar certa desvantagem, em alguns cenários, tendo que entrar em disputa direta por certas competências que não são exclusividade de nenhuma categoria, mas de várias. Tem-se observado o Serviço Social em certas disputas, sobretudo no que se refere ao trabalho com famílias, trabalho com recursos comunitários/redes socioassistenciais e trabalho em atividades de geração de renda, principalmente com alguns profissionais da Psicologia, mas em alguns cenários, com enfermeiros também.

O fazer do assistente social na Saúde Mental, na atualidade, ainda se conforma como um espaço em construção, requerendo maiores sistematizações por parte da categoria, que nem sempre investe em documentação de sua prática.

As unidades de formação acadêmica têm se debatido com várias limitações neste sentido, pois os campos de estágio curricular obrigatório têm se concentrado nos serviços tradicionais, sobretudo hospitais psiquiátricos, que comumente se conformam como hospitais universitários ou serviços ambulatoriais, conforme constatou Uchôa (2007).

Rosa e Melo (2010), ao efetivar um balanço da produção acadêmica sobre o Serviço Social na Saúde Mental no Piauí, a partir de dois cursos de Serviço Social, um de natureza pública federal e outro particular, constatam que:

[...] apesar da diversidade e riqueza de inserções de assistentes sociais nos diferentes espaços sócio ocupacionais na assistência psiquiátrica do Piauí, sobretudo a partir da reforma psiquiátrica, há parco investimento na sistematização dessas novas experiências por agentes da categoria, predominando, como visto, a análise das práticas profissionais por acadêmicos, que concentram seus estudos no modelo hospitalocêntrico, a partir de suas experiências de estágio (p. 149).

Têm se constatado a participação ativa de muitos assistentes sociais na gênese de processos de reforma psiquiátrica, em vários municípios e regiões do Brasil, a exemplo de Natal, no Rio Grande do Norte, de Campinas - SP e do Estado do Piauí, onde o protagonismo da profissão ocorreu, inclusive, na esfera da gestão da política pública municipal e estadual, perdendo-se tal fato pela ausência de registros públicos ou, em raros casos, pelo registro em livros de circulação restrita, de difícil acesso. 
Os assistentes sociais, na execução direta da política pública, de modo geral, têm muita dificuldade em sistematizar seu fazer cotidiano. Às vezes, por não terem a dimensão histórica do que lhes parece trivial no seu cotidiano interventivo; outras, por não colocarem na sua agenda cotidiana um tempo para se dedicar a essa tarefa, que aparece para muitos como "chata”, “onerosa”, de "baixa visibilidade” e estímulo. Não figura, portanto, como se fosse um trabalho como outro qualquer, impossibilitando assim a preservação da memória da profissão. Muitas vezes, o registro ainda deixa de acontecer por uma concepção distorcida do que seja uma prática profissional planejada, documentada. Numa perspectiva de que se não é cobrada institucionalmente, logo, não devo fazer, o profissional equivocadamente deixa, inclusive, de produzir um instrumento importante para a defesa do seu exercício profissional e da preservação do campo para a área do Serviço Social.

Ao mesmo tempo, os poucos profissionais que conseguem se organizar e priorizar tal tarefa arrisca ver seus registros desaparecidos, por empréstimos não devolvidos ou mesmo como lixo, pela falta de visão de parte significativa de gestores, que, para desocupar salas, muitas vezes, jogam fora toda a documentação histórica das instituições, sem ter ideia do valor histórico que representam.

Há assistentes sociais que tem o desejo de sistematizar seu fazer, mas apresentam muitas dificuldades com a escrita, sobretudo com as exigências das normas científicas/acadêmicas e também na veiculação de suas ideias.

Louva-se o empenho de alguns núcleos de pesquisa que estimulam alguns destes profissionais pioneiros a sistematizar suas práticas, com garantia de publicação de seus escritos, independente de estarem ligados a uma pós-graduação.

A Lei $n^{\circ}$ 8.662, em seu artigo $4^{\circ}$, define como competência do assistente social:

- I - elaborar, implementar, executar e avaliar políticas sociais;

- $\quad$ II - elaborar, coordenar, executar e avaliar planos, programas e projetos da área;

- III - encaminhar providências, e prestar orientação social a indivíduos, grupos e a população;

- V - orientar indivíduos e grupos de diferentes segmentos sociais, no sentido de identificar recursos e fazer uso dos mesmos no atendimento e na defesa de seus direitos;

- VI - planejar, organizar e administrar benefícios e serviços sociais; 
- $\quad$ VII - planejar, executar e avaliar pesquisas que possam contribuir para a análise da realidade social e para subsidiar ações profissionais;

- $\quad$ VII - prestar assessoria e consultoria a órgão da administração pública direta e indireta;

- IX - prestar assessoria e apoio aos movimentos sociais em matéria relacionada a políticas sociais;

- $\quad \mathrm{X}$ - planejar, organizar e administrar em SS;

- XI - realizar estudos socioeconômicos com os usuários para fins de benefícios e serviços.

Com o estabelecimento de Parâmetros para a Atuação de Assistentes Sociais na Saúde, em 2009, pelo Conselho Federal de Serviço Social, as ações dos assistentes sociais são circunscritas ao: 1) atendimento direto aos usuários, através de ações socioeducativas e ações de articulação com a equipe de saúde; 2) mobilização, participação e controle social; 3) investigação, planejamento e gestão e 4) assessoria, qualificação e formação profissional.

No geral, a ação do assistente social se concentra no primeiro plano, na relação direta com os usuários, tendo que investir mais nas outras dimensões. Mas os lugares, as funções ocupadas pelos assistentes sociais, seja como gestor, supervisor clínicoinstitucional, docente, técnico stricto sensu, vão exigir diferentes investimentos do profissional. Evidentemente terá que preservar suas atribuições exclusivas, preservando sua identidade profissional, mas será exigido de maneira distinta, em função do lugar que ocupa no serviço e diante da equipe.

Obviamente, tais contornos constituem avanços significativos para a categoria, melhor direcionando os rumos da ação e da identidade profissional do assistente social, num campo que requer maiores investimentos teórico-metodológicos e, sobretudo, sistematização de experiências, tendo em vista a crescente diversificação de demandas para o profissional de Serviço Social.

Como visto, um olhar sobre o social torna-se uma demanda para todas as categorias que atuam no âmbito do SUS.

Com certeza, o social é um conceito polissêmico e ganha contornos distintos a partir das distintas categorias profissionais que compõem o SUS. E o assistente social tem uma maneira específica de conceber e trabalhar com as diversas repercussões da Serv. Soc. \& Saúde, Campinas, SP v. 11, n. 1 (13), p. 27-50 jan./ jun. 2012 ISSN 1676-6806 
questão social, sendo instado a repensar constantemente na Saúde Mental: o que é o social na perspectiva desta categoria profissional? Como aparece e está subjacente às necessidades sociais postas pelos usuários, no campo da atenção psicossocial, em seus vários serviços?

\section{QUEM SÃO OS USUÁRIOS DOS SERVIÇOS DE SAÚDE MENTAL?}

Aparentemente essa resposta é simples: o "susdependentes", comumente os destituídos/excluídos sociais. Os segmentos mais pobres da população brasileira, que não podem acessar certos serviços pela via do mercado.

Mas outra pergunta se impõe pós Constituição Federal de 1988: o SUS não é dever do Estado e direito de todos, universalmente?

Neste diapasão, é importante reconstituir a participação do Estado brasileiro na conformação das desigualdades sociais do país, uma das primeiras manifestações sociais da questão social na saúde.

Historicamente, os serviços públicos de Saúde Mental no Brasil foram destinados massiva e preponderantemente para os segmentos mais pobres da população, ou seja, mais destituída do acesso a bens materiais e simbólicos da sociedade. Corroborando tal fato, a cidadania brasileira foi instituída como uma "cidadania regulada” (SANTOS, 1987), destinada aos trabalhadores formalmente reconhecidos.

Com essa prática, o Estado brasileiro reforçou as desigualdades sociais, impedindo a universalização de direitos a todos os brasileiros, obstaculizando os efeitos redistributivos das políticas sociais, pois

Direitos que recriam desigualdades pela sua vinculação profissional são também direitos que não se universalizam e sobrepõem às diferenças sociais uma outra clivagem que transforma em não-cidadãos os que escapam às regras do contrato. Esses são os não-iguais, os que não estão credenciados à existência cívica justamente porque privados de qualificação para o trabalho. São os pobres, figura clássica da destituição (TELLES, 1999, p. 94).

Há, consequentemente, uma fratura entre o cidadão trabalhador e o pobre, constituindo-se na prática assistencial dois sistemas de prestação de serviços na área da saúde, destinados a dois públicos distintos. De um lado, um sistema público, gratuito, destinado aos pobres, denominados indigentes. De outro lado, um sistema 
previdenciário, voltado para os segmentos de trabalhadores urbanos que contribuem para o sistema, denominados pensionistas/beneficiários.

As lutas encampadas no período de redemocratização da sociedade brasileira, sob o comando do Movimento da Reforma Sanitária brasileira, serão coroadas pelo reconhecimento da saúde como um “direito de todos e dever do Estado, garantido mediante políticas sociais e econômicas que visem à redução do risco de doença e de outros agravos e ao acesso universal e igualitário às ações e serviços para sua promoção, proteção e recuperação”, no Art. 196, da Constituição Federal de 1988, que reafirma o Sistema Único de Saúde - SUS, orientado para o setor público estatal e universal, independente da capacidade contributiva das pessoas.

Inova ao estabelecer um sistema de proteção social pela primeira vez no país amplo, igualitário e universal. Reconhece-se assim, pela primeira vez no Brasil, a cidadania plena, que rompe com a concepção de seguro social, haja vista que

A democracia implica o reconhecimento do outro, a inclusão de todos os cidadãos em uma comunidade política, a promoção da participação ativa e o combate a toda forma de exclusão. Enfim, a democracia requer o primado de um princípio de justiça social, além de sujeitos políticos e instituições (FLEURY, 2009, p. 22)

Com a reforma psiquiátrica, muitos hospitais psiquiátricos são fechados. Em estados como o Piauí, deixam de existir clínicas/hospitais psiquiátricos privados. Os serviços de urgência e emergência em Psiquiatria tornam-se exclusivamente público-estatais, muito embora existam alas particulares neste serviço, utilizado preponderantemente por pessoas vinculadas a planos de saúde privados.

Há consequentemente uma heterogeneização no perfil dos usuários de alguns CAPS, que têm abarcado segmentos de classe média, tais como estudantes universitários e profissionais liberais, embora de maneira minoritária, pela pequena demanda.

Mas o comportamento e o tipo de demanda dos segmentos médios para o SUS é bem pontual, restrito no geral à consulta médica, algumas vezes estendida ao psicólogo e à medicação. Dificilmente se sentem parte do serviço, buscando distância do público original do serviço. Procuram assegurar junto a alguns trabalhadores certos privilégios, de maneira que evitem fila, por exemplo. Agem muito mais como consumidores passivos do que cidadãos. Comportando-se desta maneira, não contribuem para a

Serv. Soc. \& Saúde, Campinas, SP v. 11, n. 1 (13), p. 27-50 jan./ jun. 2012 ISSN 1676-6806 
consolidação de uma cultura cívica democrática, em torno do serviço público, o que requer ações coletivas da equipe para tanto.

Raramente demandam o Serviço Social, mas alguns familiares - cuidadores deste segmento participam das reuniões de “famílias”.

No entanto, o assistente é reconhecido como o profissional que tem domínio sobre o trato com a pobreza.

O Serviço Social é uma profissão que tem características singulares. Ela não atua sobre uma única necessidade humana (tal como o dentista, o médico, o pedagogo...) nem tampouco se destina a todos os homens de uma sociedade sem distinção de renda ou classe. Sua especificidade está no fato de atuar sobre todas as necessidades humanas de uma dada classe social, ou seja, aquela formada pelos grupos subalternizados, pauperizados ou excluídos dos bens, serviços e riqueza dessa mesma sociedade. É por isso que os profissionais de Serviço Social atuam, basicamente, na trama das relações de conquista e apropriação de serviços e poder pela população excluída e dominada (NETTO; FALCÃO, 1987, p. 51).

Atuando sobre as necessidades sociais dos segmentos subalternizados, o assistencial passa a constituir uma demanda central para o assistente social, muito embora atue em várias frentes de trabalho, tais como ações socioeducativas, a gestão, a formação profissional, dentre outras.

Consequentemente, essa centralidade traz subjacentes várias implicações para o dia a dia profissional, já que várias vezes o usuário e seus familiares veem o assistente social como o profissional que facilita ou restringe o usufruto de certos "benefícios".

O acesso a vale transporte, que assegura o deslocamento de casa para o CAPS, o que em muitos serviços é indispensável para garantir a acessibilidade, haja vista a não incorporação, em alguns municípios/estados, da pessoa com transtorno no rol dos usuários do “passe livre”, em geral também é gerido pelo assistente social, o qual deve estabelecer critérios de eletividade para tanto, em virtude da restrição quantitativa, que não permite a universalidade nem integralidade do cuidado.

Esta tarefa tem consumido muito tempo de trabalho de alguns assistentes sociais, em alguns serviços de saúde mental, o que limita tais profissionais a trabalho burocrático, disciplinar, controlador, sem conseguir reverter essa tendência.

Há serviços em que o trabalho se concentra na intermediação com a perícia médica do Instituto Nacional de Seguridade Social (INSS), haja vista as contradições na operacionalização do Benefício de Prestação Continuada (BPC), um serviço do campo Serv. Soc. \& Saúde, Campinas, SP v. 11, n. 1 (13), p. 27-50 jan./ jun. 2012 ISSN 1676-6806 
da Assistência, mas gerido conforme a lógica da Previdência, como analisa Maciel (2008).

Na dinâmica histórica, o acesso a determinados direitos sociais tendeu a restringir direitos civis, havendo tensões entre esses direitos, como bem analisa Norberto Bobbio (1992).

Exemplo dessa tensão na atualidade se expressa no acesso ao Benefício de Prestação Continuada (BPC), que, em muitas circunstâncias, ainda é imposto a interdição da pessoa com transtorno mental, mesmo que mantenha várias dimensões de sua capacidade civil intacta e que a lei tenha suprimido tal exigência.

O Conselho Federal de Psicologia lançou em 2008/9 uma cartilha intitulada “Benefício de Prestação Continuada: não abra mão da sua cidadania”, informando que a interdição judicial não é necessária (www.pol.org.br) e esclarecendo os aspectos legais inerentes ao fato.

A literatura do Serviço Social vem sinalizando o quão excludente são os critérios de acesso ao BPC, sendo um deles a renda mensal per capita ser inferior a 1/4 do salário mínimo. Entretanto, as intensas restrições de acesso ao BPC e os rigores no processo de submissão a exame médico pericial e laudo realizado pelos serviços de perícia médica do Instituto Nacional do Seguro Social - INSS - têm causado vários constrangimentos e dificuldades em seu usufruto.

Algumas pessoas com transtornos mentais, submetidas à "violência institucional" que tiveram o direito negado, tendem a retornar ao serviço pericial simulando crises psicóticas, com a finalidade de convencer os médicos de que realmente têm um transtorno mental, em função de não bastar a informação do diagnóstico referenciado ao CID-10. Aliás, não é qualquer enfermidade do CID-10 que é considerada incapacitante e, portanto, passível de usufruto do BPC.

Nesse mesmo horizonte, observa-se que um número significativo de familiares insiste na internação integral em hospitais psiquiátricos, o que na concepção de alguns deles denotaria a gravidade e incapacidade do caso, também como estratégia de convencimento dos médicos da perícia do INSS.

Consequentemente, limita-se a avaliação da pessoa e de suas capacidades à enfermidade, subsumindo-se a pessoa ao transtorno, ficando o segundo em evidência. Há ainda destaque para o transtorno mental e seus sintomas, num reforço à visão biomédica, confrontando o que preceitua a reforma psiquiátrica, com a lei nº 10.216. 
Por sua vez, a partir do ano 2.000, o governo federal passa a dar significativo enfoque para as ações de inclusão da pessoa com transtorno mental no mercado de trabalho, a partir de cooperativas, de oficinas de geração de renda e trabalho. Alguns estados, como o Rio de Janeiro e Rio Grande do Sul, passam a implementar programas de bolsa trabalho, visando a profissionalização e inclusão pelo trabalho.

Neste contexto, várias modalidades de “trabalho protegido” têm início, com apoio governamental. Em novembro de 2004, os Ministérios da Saúde e do Trabalho realizaram Oficina de Experiências de Geração de Renda e Trabalho (BRASIL, 2005). Pela Portaria Interministerial $n^{0}$ 353, de 07 de março de 2005, consolida-se a relação entre Saúde Mental e Economia Solidária.

Com isso, o Estado passa a investir em ações afirmativas, permitindo que outras dimensões da identidade da pessoa com transtorno mental possam ganhar visibilidade pública.

Mas, embora os supracitados ministérios cataloguem um número significativo de experiências na área de geração de emprego e renda para pessoas com transtornos mentais, o próprio Ministro da Saúde admite que "são experiências frágeis e de pequena sustentabilidade”. E não alteraram substancialmente o imaginário social em relação à pessoa com transtorno mental, que depende de ações conjugadas com a mídia e educação, na área de direitos humanos.

Outro limite é como enfrentar um contexto de escassez de recursos e desinvestimentos do Estado, no campo social, com demandas cada vez mais heterogêneas, de diferentes segmentos minoritários, que disputam os parcos recursos, buscando carrear o máximo para si, forjando lutas pontuais, corporativas e, assim, restritas, não universais. Por exemplo, houve tentativa de extensão das cotas legais de inclusão no mercado de trabalho de pessoas com deficiência para pessoas com transtornos mentais, mas alguns Conselhos dos Deficientes "entraram com uma representação, por causa da nomenclatura da Lei” (BRASIL, 2005, p. 49). Ou seja, as próprias pessoas com deficiência resistem à extensão da lei para as pessoas com transtornos mentais, forjando uma situação em que tal segmento se torna "os excluídos dos excluídos” (Ibid., p. 64).

Os diferentes transtornos mentais afetam diferentemente a vida das pessoas. Aqueles que não alteram as dimensões cognitivas permitem maior inclusão social do que, por exemplo, quadros como de esquizofrenia refratária, que tendem a afetar: o funcionamento social (habilidades de trabalho e relações sociais); ocupacional; Serv. Soc. \& Saúde, Campinas, SP v. 11, n. 1 (13), p. 27-50 jan./ jun. 2012 ISSN 1676-6806 
cognição e relações afetivas (a rede de amizade empobrece, no mercado afetivo e matrimonial, tende a haver alijamento deste segmento).

Estudos sugerem que pessoas com transtorno mental que se mantêm empregadas ou desenvolvem suas habilidades laborativas têm maior satisfação com a vida. Assim, “o trabalho é percebido como elemento de realização pessoal, aumentando a autoestima e melhorando a visão que o paciente tem sobre si mesmo e sobre a doença” (WAGNER, FLECK, 2008).

Esse fato possibilita ainda, a intensificação do poder contratual da pessoa com transtorno mental, pois, a filiação de qualquer ser humano ao mundo do trabalho, sobretudo na sociedade capitalista, em que a identidade das pessoas se vincula à sua inserção ou des(inserção) no mercado de trabalho, permite maior ampliação de contatos sociais, uma fonte de renda que viabiliza transações pessoais, comerciais e até temporal, haja vista permitir uma programação da vida futura.

Até o governo Lula, o acesso ao BPC também tolhia possibilidades de inserção no mercado de trabalho, uma vez que, se o beneficiário tivesse um trabalho formal, materializado na carteira assinada, perdia o benefício, tendo muitas dificuldades em reavê-lo, caso ficasse desempregado. O $\S 9^{\circ}$ do Artigo 20 da LOAS atualizada ${ }^{3}$ procura $^{\circ}$ reverter tal tendência. Mas toda uma cultura e temor foi gerada em torno disso, o que muitas vezes dificulta que o beneficiário aceite se empregar, até por pressão das famílias, pois em muitos cenários o BPC é a única fonte de renda do grupo familiar todo.

Destarte, houve historicamente um desestímulo no desenvolvimento e na ampliação das habilidades e competências laborativas da pessoa com transtorno mental, como beneficiária do BPC, havendo conflitos intensos e envolvendo vários aspectos que o Serviço Social tem contribuído de maneira mais densa para reverter.

O benefício não gera direito, mas pode permitir outras possibilidades de vida. O trabalho não é garantido, até pelo complicador do estigma social que historicamente se construiu em torno da pessoa com transtorno mental, a-priori, como perigosa e incapaz.

Às vezes o Serviço Social entra em zona de litigância com a Psicologia em torno da questão do BPC. A literatura de natureza sociológica e psicanalítica interpreta que a busca por certos direitos/benefícios pode figurar como "ganhos/lucros secundários” da enfermidade, em função da cultura social e familiar poupar os enfermos de certos

\footnotetext{
${ }^{3}$ http://www.modelodepeticoes.com.br/legislacao/45_lei_organica_da_assistencia_social_loas.php
}

Serv. Soc. \& Saúde, Campinas, SP v. 11, n. 1 (13), p. 27-50 jan./ jun. 2012 ISSN 1676-6806 
deveres no interior do grupo/sociedade. Também pode denotar uma compensação pela impossibilidade mesma para o trabalho de alguns membros do grupo; da existência de um membro a menos como gerador de renda para seu grupo de origem ou até para o familiar cuidador que, no geral, é obstaculizado a se constituir como gerador de renda em função do trabalho inerente ao provimento de cuidado doméstico colidir com o tempo do trabalho formal.

Essa é uma questão complexa e como tal deve ser enfrentada. Não é meramente uma questão técnica, mas envolve uma multiplicidade de aspectos, inclusive no desenvolvimento dos projetos terapêuticos.

$\mathrm{Na}$ interação com pessoas com uso dependente de substâncias químicas, é frequente o consenso entre os familiares que aquela pessoa não deva ter acesso ao BPC ou outra modalidade de transferência de renda. Há o temor de que a pessoa venha a utilizar o dinheiro todo para manter a dependência.

Depois de anos de acompanhar um filho na luta pela abstinência, consignada às duras penas e sentimentos de incerteza, “tudo” o que uma mãe quer é que seu filho fique longe de substâncias psicoativas, mesmo que isso signifique que nunca mais maneje dinheiro ou até mesmo fique com a vida "paralisada”, tendência que deve ser revertida pela equipe.

Com a demanda afirmativa para obter o BPC, Pinto (2007), ao analisar a demanda de familiares por benefícios, a partir de uma leitura psicanalítica, associa-a ao Nome-do-Pai (ibid., p. 63), provocando um diálogo com o Serviço Social sobre a matéria, afirmando que,

[...] uma vez que estão aprisionados numa única direção, que é a dos direitos sociais. Não se trata aqui de negligenciar esta questão, mas de não tomá-la de pronto, sem escutar o que cada responsável quer dizer quando diz que necessita de um "benefício (ibid, p. 40) [...] Segundo a autora, a concessão de um benefício pode aprisioná-las num lugar de objeto e de gozo para os pais (ibid , p. 66).

Tais colocações instam para o pensar sobre as consequências e contradições subjacentes à demanda por benefícios, se os mesmos potencializam ou restringem novas possibilidades de vida, interlocução com outras políticas sociais e relações sociais.

Qual seu significado para a pessoa com transtorno mental e para seus familiares? O que muda em suas vidas? 
O exemplo dos moradores de Serviços Residenciais Terapêuticos, beneficiários do Programa de Volta Para Casa, é evidente no sentido de mudanças positivas em suas vidas.

Muitas pessoas com transtornos mentais, mesmo com limitações impostas pela enfermidade ou estigma, desejam trabalhar, aprender, desenvolver outras competências sociais. Em que medida o benefício ou aposentadoria auxilia ou obstaculiza tais projetos?

São questões importantes para o Serviço Social contribuir para suscitar debate e equacionar, de maneira cidadã, que assegure direitos.

Evidentemente os direitos sociais configuram direitos conquistados e que devem ser viabilizados e assegurados, mas não podem ser despotencializados nem despolitizados. Na Saúde Mental, devem contribuir para a construção de uma identidade plural da pessoa com transtorno mental, com a sua inserção em outros lugares sociais, propiciando trocas e novo reconhecimento social.

Por outro lado, em uma sociedade e cultura em que o trabalho é central na construção da identidade dos sujeitos, a luta pela inclusão no trabalho também passa a constituir pauta de reivindicações das pessoas em desvantagem social, dentre as quais, as pessoas com transtorno mental, exigindo de todos, mas em particular dos assistentes sociais, repensar estratégias de ação no combate ao estigma e reconhecimento de outras competências das pessoas com transtorno mental, em conjunto com outros atores e políticas sociais.

\section{CONSIDERAÇÕES FINAIS}

As manifestações da questão social que atravessam a Saúde Mental, no plano macrossocial, no geral, envolvem as repercussões das desigualdades sociais da sociedade capitalista; a violência institucional; o estigma; a exclusão de direitos, dentre outros.

O Serviço Social embora figure na Saúde Mental há muito tempo, pouco produziu sobre suas várias inserções no campo da saúde mental contemporaneamente, tendo pouco e recente acúmulo teórico.

O debate no Serviço Social está apenas no início, muito há que acrescentar para fomentar as discussões, sobretudo no plano da pesquisa, discutindo o perfil socioeconômico dos usuários; a análise e apropriação das diversas manifestações da Serv. Soc. \& Saúde, Campinas, SP v. 11, n. 1 (13), p. 27-50 jan./ jun. 2012 ISSN 1676-6806 
questão social, a partir da Saúde Mental e a operacionalização dos princípios do SUS e, sobretudo, em relação à intersetorialidade e no trabalho com redes socioassistenciais.

\section{REFERÊNCIAS}

BRASIL. Política Nacional de Humanização. Brasília: Ministério da Saúde, 2004.

BOBBIO, N. A era dos direitos. Rio de Janeiro: Editora Campus, 1992.

CAMPOS, G. W. S. Saúde Paidéia. $3^{\text {a }}$ Ed. São Paulo: Hucitec, 2007.

CAMPOS, R. O.; FURTADO, J. P.; PASSOS, E.; BENEVIDES, R. p. 398-420. À guisa de conclusão: La clé dês champs! In: CAMPOS, R. O; FURTADO, J. P; PASSOS, E.; BENEVIDES, R. Pesquisa qualitativa em Saúde Mental: desenho participativo e efeitos de narratividade. São Paulo: Hucitec, 2008.

CONSELHO FEDERAL DE PSICOLOGIA. Benefício de Prestação Continuada: não abra mão da sua cidadania. Disponível em www.pol.org.br.Acesso dia 10/03/2012.

CONSELHO FEDERAL DE SERVIÇO SOCIAL. Legislação e resoluções sobre o trabalho do/a assistente social. Brasília: CFESS, 2011.

CRESS-RJ. O Serviço Social Clínico e o projeto ético político do Serviço Social. Em foco. Rio de Janeiro: CRESS, 2003.

CRESS. Atribuições privativas do Assistente Social e o "Serviço Social Clínico”. Em Foco. Rio de Janeiro: CRESS, 2004.

CRESS $7^{\text {a }}$ RJ. Assistente social: ética e direitos. Coletânea de leis e resoluções. $4^{\mathrm{a}}$ Ed. Rio de Janeiro: CRESS 7ª R - RJ, 2005.

EIRAS, A. A. L.T.S. Problematizações acerca do trabalho com grupos no Serviço social brasileiro. P. 121-158. In: VASCONCELOS, E. M. (Org). Abordagens psicossociais volume III. Perspectivas para o Serviço Social. São Paulo: Hucitec, 2009.

FLEURY, S. Coesão e seguridade. p. 10-27. Seguridade social, cidadania e saúde. LOBATO, L. V; FLEURY, S. Rio de Janeiro: CEBES, 2009.

HELLER, A. O cotidiano e a história. Rio de Janeiro: Paz e Terra, 1989. LANCETTI, A. Clínica peripatética. $3^{\mathrm{a}}$ Ed. São Paulo: Hucitec, 2008.

MACIEL, C. A. B. Benefício de prestação continuada: as armadilhas... Presidente Venceslau - SP: Letras à margem, 2008.

MERHY, E. E. Saúde: a cartografia do trabalho vivo. $3^{\text {a }}$ Ed. São Paulo: Hucitec, 2007.

NETTO, JP; FALCÃO, M.C.. Cotidiano: conhecimento e critica. São Paulo: Cortez, 1987.

Serv. Soc. \& Saúde, Campinas, SP v. 11, n. 1 (13), p. 27-50 jan./ jun. 2012 ISSN 1676-6806 
PEREIRA, I. C. G. Do ajustamento à invenção da cidadania: serviço social, saúde mental e intervenção na família no Brasil. P. 217-262. IN: VASCONCELOS, E. M. (Org) Saúde Mental e Serviço Social: o desafio da subjetividade e da interdisciplinaridade. São Paulo: Cortez, 2000.

PINTO. RF. CAPSI para crianças e adolescentes autistas e psicóticos. Rio de Janeiro: Editora Museu da República, 2007.

RAMOS, R. A. As representações sociais sobre a prática profissional do assistente social nos Centros de Atenção Psicossocial no Ceará. UFPE/ Programa de Pós Graduação em Serviço Social. Mestrado. Recife, 2003.

ROTELLI, F. Desinstitucionalização. São Paulo: Hucitec, 1990.

ROSA, L. C. dos S; MELO, T.M.F.S. Balanço da produção acadêmica sobre Serviço Social na assistência psiquiátrica do Piauí. FRANCO, C. M.B; VASCONCELOS, J. G.; FRANCO, P. M.B. Os diferentes olhares do cotidiano profissional. Fortaleza; Edições UFC, 2010 P. 139-151.

SANTOS, W.G. Cidadania e justiça: A política social na ordem brasileira. $2^{\mathrm{a}}$ Ed. Rio de Janeiro: Campus, 1987.

SARACENO, B. Libertando identidades: da reabilitação psicossocial à cidadania possível. Rio de Janeiro: Instituto Franco Basaglia/TeCorá, 1999.

SCHELB, G. Viver é coisa perigosa: orientações para soluções de conflitos. Brasília: Thesaurus, 2008.

TELLES, V. da S. Sociedade civil e construção de espaços públicos. P. 90-102. In: DAGNINO, E. (Org). Anos 90: política e sociedade no Brasil. São Paulo: Brasiliense, 1994.

UCHÔA, R. Resultados da pesquisa Serviço Social interfaces com a saúde? O ensino da política de saúde na formação profissional dos assistenciais sociais no Brasil. p. 185-200. In: Temporalis, ano VII, n. 13. jan-jun, 2007.

VASCONCELOS, E. M. (Org.) Saúde Mental e Serviço Social: o desafio da subjetividade e da interdisciplinaridade. São Paulo: Cortez, 2000.

WAGNER, L. C. FLECK, M.P.A. Avaliação da qualidade de vida na esquizofrenia. p.147-56. FLECK, M. P. A. e colaboradores. A avaliação de qualidade de vida - Guia para profissionais de Saúde. Porto Alegre: Artmed, 2008. http://www.modelodepeticoes.com.br/legislacao/45_lei_organica_da_assistencia_sociall oas.php, acessado em 17/04/2012. 
